\title{
Glifosato aplicado com diferentes concentrações de uréia ou sulfato de amônio para dessecação de plantas daninhas
}

\author{
Saul Jorge Pinto de Carvalho(1), Ana Carolina Ribeiro Dias ${ }^{(1)}$, Virginia Damin ${ }^{(2)}$, \\ Marcelo Nicolai(1) e Pedro Jacob Christoffoleti(1)
}

\begin{abstract}
(1)Escola Superior de Agricultura Luiz de Queiroz (Esalq), Departamento de Produção Vegetal, Caixa Postal 09, CEP 13418-900 Piracicaba, SP. E-mail: sjpcarvalho@yahoo.com.br, acrdias@esalq.usp.br, marcelon@esalq.usp.br, pjchrist@esalq.usp.br ${ }^{(2)}$ Esalq, Departamento de Solos e Nutrição de Plantas. E-mail: virginia@esalq.usp.br
\end{abstract}

\begin{abstract}
Resumo - Este trabalho foi desenvolvido com o objetivo de avaliar a eficácia do herbicida glifosato, para a dessecação de trapoeraba (Commelina benghalensis) e outras plantas daninhas, quando combinado a diferentes concentrações de sulfato de amônio ou uréia. Foram conduzidos três experimentos com tratamentos semelhantes: dois em campo e um em casa de vegetação. Os tratamentos aplicados em campo foram: glifosato (360 $\mathrm{g}$ ha $^{-1}$ de e.a.), isolado ou acrescido de quatro concentrações de sulfato de amônio $\left(2,5,5,10\right.$ e $\left.20 \mathrm{~g} \mathrm{~L}^{-1}\right)$ ou uréia $(1,5$, 3,6 e $12 \mathrm{~g} \mathrm{~L}^{-1}$ ); glifosato a $720 \mathrm{~g} \mathrm{ha}^{-1}$ de e.a., aplicado isoladamente; e testemunha sem aplicação. Em casa de vegetação, para o controle específico da trapoeraba, as doses de glifosato foram elevadas para 720 (isolado e nas combinações) e $1.440 \mathrm{~g} \mathrm{ha}^{-1}$ de e.a. A adição de sulfato de amônio à calda do glifosato elevou o controle das plantas daninhas em campo, para as concentrações com até $10 \mathrm{~g} \mathrm{~L}^{-1}$. O herbicida glifosato não foi eficaz no controle da trapoeraba, em nenhumas das doses usadas. A adição de uréia não promoveu incrementos de controle em condição de campo; porém, para concentrações de até $6 \mathrm{~g} \mathrm{~L}^{-1}$, melhorou o controle da trapoeraba, na avaliação conduzida aos 28 dias após aplicação.
\end{abstract}

Termos para indexação: Commelina benghalensis, controle químico, eficácia, herbicida.

\section{Glyphosate applied with different concentrations of urea or ammonium sulfate for weed desiccation}

\begin{abstract}
This work was developed with the objective of evaluating glyphosate efficacy for Bengal dayflower (Commelina benghalensis) and other weeds desiccation, when combined to different concentrations of ammonium sulfate or urea. Three experiments were carried out with similar treatments: two in field conditions and one in greenhouse. Treatments applied in field conditions were: glyphosate at $360 \mathrm{~g}^{-1}$ a.e., isolated or combined to four concentrations of ammonium sulfate $\left(2.5,5,10\right.$, and $\left.20 \mathrm{~g} \mathrm{~L}^{-1}\right)$ or urea $(1.5,3,6$, and $12 \mathrm{~g} \mathrm{~L}^{-1}$ ); glyphosate at $720 \mathrm{~g} \mathrm{ha}^{-1}$ a.e., applied isolately; and checks without application. In greenhouse, for the specific control on Bengal dayflower, glyphosate rates were increased to 720 (isolated or in combination) and to $1,440 \mathrm{~g} \mathrm{ha}^{-1}$ a.e. Ammonium sulfate addition to glyphosate spray solution increased field weed control, when concentrations up to $10 \mathrm{~g} \mathrm{~L}^{-1}$ were used. None of the glyphosate rates were efficient to control Bengal dayflower. Urea addition to spray solution did not improve weed control in field conditions; however, it increased Bengal dayflower control for concentrations up to $6 \mathrm{~g} \mathrm{~L}^{-1}$, at the evaluation after 28 days of application.
\end{abstract}

Index terms: Commelina benghalensis, chemical control, efficacy, herbicide.

\section{Introdução}

Há crescente pressão da sociedade, atualmente, pela adoção de sistemas de produção conservacionistas, que têm por base o revolvimento mínimo do solo e a manutenção da cobertura vegetal em sua superfície. Com este objetivo, o sistema de semeadura direta ou o de cultivo mínimo têm sido largamente utilizados por produtores da América do Sul. Contudo, esses sistemas alteram a dinâmica do manejo de plantas daninhas, em razão das restrições impostas pela palhada à aplicação de alguns herbicidas diretamente ao solo (Christoffoleti et al., 2007).

O glifosato é um herbicida muito útil para a adoção em sistemas de baixo impacto ambiental, em razão de seu amplo espectro de controle e baixa toxicidade a organismos não alvo (Trigo \& Cap, 2003; Christoffoleti et al., 2008). Trata-se de herbicida não seletivo, de ação sistêmica, usado no controle de plantas daninhas anuais e perenes e na dessecação de culturas de cobertura (Rodrigues \& Almeida, 2005; Timossi et al., 
2006). A molécula inibe a enzima EPSPs (enol piruvil shiquimato fosfato sintase), que participa da rota de síntese dos aminoácidos aromáticos fenilalanina, tirosina e triptofano. Sua absorção é um processo bifásico, que envolve rápida penetração pela cutícula, seguida de absorção simplástica lenta dependente de fatores como a idade da planta, condições ambientais, surfactantes e concentração do herbicida na calda (Monquero et al., 2004).

$\mathrm{O}$ advento das culturas geneticamente modificadas, quanto à tolerância a herbicidas, também tem contribuído sobremaneira para a maior adoção do glifosato (Young et al., 2003); e problemas decorrentes de seu uso repetitivo já foram relatados, entre os quais a seleção de espécies tolerantes ou de biótipos de plantas daninhas resistentes ao produto (Monquero \& Christoffoleti, 2003; Christoffoleti et al., 2008). A trapoeraba (Commelina benghalensis L.), por exemplo, tem sido selecionada em áreas com sucessivas aplicações de glifosato, por sua tolerância ao herbicida - entre outras características -, a qual está correlacionada à sua habilidade em metabolizar a molécula a compostos menos tóxicos (Monquero \& Christoffoleti, 2003; Monquero et al., 2004).

Em razão da importância do glifosato para a agricultura mundial, estudos têm sido conduzidos com o objetivo de avaliar a contribuição de diferentes variáveis em sua eficácia, das quais se podem destacar: dose (Jordan et al., 1997), volume de calda (O'Sullivan et al., 1981; Ramsdale et al., 2003), qualidade da água (Thelen et al., 1995; Ramos \& Durigan, 1998; Gauvrit, 2003), estádio fenológico das plantas daninhas (Durigan, 1992; Jordan et al., 1997) e atividade de adjuvantes (O'Sullivan et al., 1981; Pratt et al., 2003; Nurse et al., 2008).

A adição de fontes nitrogenadas, como adjuvantes à calda do herbicida, tem sido relacionada à redução de doses, ao antagonismo de cátions em água dura e à melhor absorção e translocação da molécula do glifosato(Costa \&Appleby, 1986; Salisbury et al., 1991; Nalewaja \& Matysiak, 1993; Maschhoff et al., 2000; Pratt et al., 2003; Young et al., 2003; Mueller et al., 2006); porém, poucos estudos foram desenvolvidos quanto à realidade brasileira, em que a composição específica da comunidade infestante é diferente, o que pode ter reflexos sobre os resultados.

Este trabalho foi desenvolvido com o objetivo de avaliar a eficácia do herbicida glifosato, na dessecação de plantas daninhas, com destaque para a trapoeraba, quando combinado a diferentes concentrações de sulfato de amônio ou uréia.

\section{Material e Métodos}

Três experimentos foram desenvolvidos em Piracicaba, SP $\left(22^{\circ} 42^{\prime} 30^{\prime \prime} \mathrm{S}, 4^{\circ} 38^{\prime} 0^{\prime \prime} \mathrm{W}\right.$ e $546 \mathrm{~m}$ de altitude), entre abril e julho de 2008: dois em campo e um em casa de vegetação. O primeiro experimento em campo foi instalado em área do Departamento de Produção Vegetal, da Escola Superior de Agricultura Luiz de Queiroz (Esalq/USP). O solo foi classificado como Nitossolo Vermelho eutrófico, de textura argilosa, $\mathrm{pH} 5,4$, com 2,5\% de matéria orgânica e $69 \%$ de saturação por bases. A área estava densamente infestada por plantas daninhas (40 plantas $\mathrm{m}^{-2}$ ), com destaque para o apaga-fogo (Alternanthera tenella), em pleno florescimento, que foi caracterizada como a espécie dominante $(85 \%)$.

$\mathrm{O}$ segundo experimento em campo foi instalado em área da Fazenda Areão, da Esalq/USP, em Piracicaba. O solo foi classificado como Argissolo Eutroférrico, de textura argilosa, $\mathrm{pH} 5,2$, com 2,8\% de matéria orgânica e $60 \%$ de saturação por bases. A densidade total de plantas daninhas foi estimada em 120 plantas $\mathrm{m}^{-2}$, composta por: $30 \%$ de guanxuma (Sida spp.), em pré-florescimento; $15 \%$ de capim-amargoso (Digitaria insularis), em florescimento; $20 \%$ de capim-rabode-raposa (Setaria geniculata), em florescimento; $20 \%$ de capim-carrapicho (Cenchrus echinatus), em florescimento e $15 \%$ de outras espécies, com distribuição heterogênea.

$\mathrm{O}$ terceiro experimento foi conduzido em casa de vegetação, no Departamento de Produção Vegetal da Esalq/USP, em vasos de plástico, com capacidade para $0,5 \mathrm{~L}$, preenchidos com mistura de substrato comercial e vermiculita, na proporção 2:1, devidamente fertilizados com $200 \mathrm{mg}$ de $\mathrm{N}, \mathrm{P}_{2} \mathrm{O}_{5}$ e $\mathrm{K}_{2} \mathrm{O}$. Em cada vaso, cultivou-se uma planta de trapoeraba que, no momento da aplicação do herbicida, continha 5-6 folhas no ramo principal, 4-5 ramos laterais basais e média de $0,15 \mathrm{~m}$ de altura.

Em campo, cada parcela contou com as dimensões de $2,5 \times 4 \mathrm{~m}$, com área total de $10 \mathrm{~m}^{2} \mathrm{e}$ área útil de $8 \mathrm{~m}^{2}$. Em todos os experimentos, o delineamento experimental foi o de blocos ao acaso, com 11 tratamentos. Adotaramse três repetições para as conduções em campo e cinco 
para o experimento em casa de vegetação. Os tratamentos aplicados em campo foram: glifosato (Roundup Original, $360 \mathrm{~g} \mathrm{ha}^{-1}$ de e.a.), isolado ou acrescido de quatro concentrações de sulfato de amônio $(2,5,5,10$ e $\left.20 \mathrm{~g} \mathrm{~L}^{-1}\right)$ ou uréia $\left(1,5,3,6\right.$ e $\left.12 \mathrm{~g} \mathrm{~L}^{-1}\right)$; glifosato a $720 \mathrm{~g} \mathrm{ha}^{-1}$ de e.a., aplicado isoladamente; e testemunha sem aplicação. Em casa de vegetação, para o controle da trapoeraba, as doses de glifosato foram elevadas para 720 (isolado e nas combinações) e $1.440 \mathrm{~g} \mathrm{ha}^{-1}$ de e.a. (Tabela 1). As doses de glifosato foram baseadas nas recomendações usuais para espécies de plantas daninhas (Rodrigues \& Almeida, 2005).

A aplicação de herbicidas em campo, na primeira área, foi realizada em 11/4/2008, das $11 \mathrm{~h} 20$ às 11h45. No momento das aplicações, os parâmetros meteorológicos médios foram: umidade relativa (UR), $85 \%$; temperatura (T), $26,9^{\circ} \mathrm{C}$; céu sem nuvens, e ventos de $1,5 \mathrm{~km} \mathrm{~h}^{-1}$. A primeira chuva foi registrada 12 horas após a aplicação, com cerca de $0,5 \mathrm{~mm}$ de precipitação. A aplicação de herbicidas, na segunda área, em campo, também foi realizada em 11/4/2008, das $15 \mathrm{~h} 50$ às $16 \mathrm{~h} 20$. No momento das aplicações, os parâmetros meteorológicos médios foram: UR, 63,5\%; $\mathrm{T}, 30,4^{\circ} \mathrm{C}$; céu encoberto, com $25 \%$ de nuvens, e ventos de $4,5 \mathrm{~km} \mathrm{~h}^{-1}$. A primeira chuva foi registrada 7,5 horas após a aplicação, com os mesmos $0,5 \mathrm{~mm}$. As precipitações e a temperatura média diária do período em que o experimento esteve no campo, estão apresentadas na Figura 1.

Para as aplicações em campo, utilizou-se pulverizador costal pressurizado por $\mathrm{CO}_{2}$, acoplado a uma barra de pulverização com largura útil de $2 \mathrm{~m}$, com quatro pontas do tipo jato plano, 110.02 , espaçadas em $0,50 \mathrm{~m}$, calibrado para volume de calda proporcional a $200 \mathrm{~L} \mathrm{ha}^{-1}$. Em casa de vegetação, realizou-se a aplicação em 10/6/2008, em câmara de pulverização pressurizada por ar comprimido, equipada com uma única ponta do tipo jato plano, 80.02, também calibrada para volume de calda de $200 \mathrm{~L} \mathrm{ha}^{-1}$. A água utilizada nas aplicações passou por tratamento comum para distribuição pública, realizado na própria Esalq/USP, cuja análise está apresentada na Tabela 2.

As variáveis avaliadas foram: controle percentual aos 14, 21 e 28 dias após a aplicação (DAA); e massa de matéria seca residual aos 28 DAA. Para as avaliações de controle, utilizou-se escala que variou de 0 a $100 \%$, em que zero representou a ausência de sintomas e 100 a morte de todas as plantas. Para avaliar a massa de matéria seca, em campo, um quadro de madeira de 0,5x0,5 m foi lançado uma vez, em área representativa de cada parcela. Todo o material vegetal presente na área do quadrado foi cortado rente à superfície do solo e secado em estufa $\left(70^{\circ} \mathrm{C}\right)$ até massa constante. Em casa de vegetação, cortaram-se as plantas de trapoeraba rente à superfície do substrato e também se procedeu à secagem em estufa.

Osdados obtidos em campo foram submetidosà análise por grupo de experimentos, com aplicação do teste $\mathrm{F}$, na análise da variância. Separadamente, analisaram-se os dados obtidos em casa de vegetação, também por meio da aplicação do teste F. Quando os efeitos dos tratamentos foram significativos, aplicou-se teste $t$, para a comparação das médias entre os experimentos, e o teste de Scott-Knott para os agrupamentos das médias dos tratamentos (Scott \& Knott, 1974), ambos a 5\% de probabilidade.

\section{Resultados e Discussão}

Nos experimentos desenvolvidos em campo, não foi identificado efeito das diferentes conduções

Tabela 1. Tratamentos adotados nos experimentos em campo e em casa de vegetação.

\begin{tabular}{|c|c|c|c|c|c|c|}
\hline \multirow[t]{3}{*}{ № } & \multicolumn{3}{|c|}{ Herbicida } & \multicolumn{3}{|c|}{ Fertilizante nitrogenado } \\
\hline & \multirow[t]{2}{*}{ Condição } & \multicolumn{2}{|c|}{ Dose ( $\mathrm{g} \mathrm{ha}^{-1}$ de e.a.) } & \multirow[t]{2}{*}{ Tipo } & \multicolumn{2}{|c|}{ Dose $^{(1)}$} \\
\hline & & Campo & Casa de vegetação & & $\left(\mathrm{g} \mathrm{L}^{-1}\right)$ & $\left(\mathrm{kg} \mathrm{ha}^{-1}\right)$ \\
\hline 1 & Ausente & 0 & 0 & Ausente & 0,0 & 0,0 \\
\hline 2 & Glifosato $^{(2)}$ & 360 & 720 & Ausente & 0,0 & 0,0 \\
\hline 3 & Glifosato & 360 & 720 & Sulfato de amônio & 2,5 & 0,5 \\
\hline 4 & Glifosato & 360 & 720 & Sulfato de amônio & 5,0 & 1,0 \\
\hline 5 & Glifosato & 360 & 720 & Sulfato de amônio & 10,0 & 2,0 \\
\hline 6 & Glifosato & 360 & 720 & Sulfato de amônio & 20,0 & 4,0 \\
\hline 7 & Glifosato & 360 & 720 & Uréia & 1,5 & 0,3 \\
\hline 8 & Glifosato & 360 & 720 & Uréia & 3,0 & 0,6 \\
\hline 9 & Glifosato & 360 & 720 & Uréia & 6,0 & 1,2 \\
\hline 10 & Glifosato & 360 & 720 & Uréia & 12,0 & 2,4 \\
\hline 11 & Glifosato & 720 & 1.440 & Ausente & 0,0 & 0,0 \\
\hline
\end{tabular}

${ }^{(1)}$ Volume de calda proporcional a $200 \mathrm{~L} \mathrm{ha}^{-1} \cdot{ }^{(2)}$ Roundup original, $360 \mathrm{~g} \mathrm{~L}^{-1}$ de e.a. 
(Tabela 3, $\mathrm{F}_{\text {(Exp) }}$ ), em relação a quaisquer das avaliações realizadas, de forma que os dados apresentados são as médias dos dois experimentos analisadas em conjunto. Pelo controle mínimo previsto na legislação como de $80 \%$, aos 14 DAA, observou-se que a aplicação de glifosato a $360 \mathrm{~g} \mathrm{ha}^{-1}$ de e.a. não foi eficaz no controle das plantas daninhas, quando administrado de forma isolada ou com adição de uréia (Tabela 3). É importante que se registre que: no instante das aplicações, não havia sedimentos ou excessiva quantidade de poeira sobre as folhas, em razão da ocorrência de chuva na véspera; não ocorreu chuva logo após a aplicação; e que as condições meteorológicas foram adequadas à eficácia dos herbicidas (Figura 1).

A aplicação de glifosato a $720 \mathrm{~g} \mathrm{ha}^{-1}$ de e.a. garantiu adequados níveis de controle, superiores a $90 \%$, aos 14 DAA. A adição de 2,5 ou $10 \mathrm{~g} \mathrm{~L}^{-1}$ de sulfato de amônio à calda, na menor dose de glifosato, proporcionou controles semelhantes ao da maior dose, o que é evidência de efeito inicial positivo da combinação, nessas dosagens (Tabela 3).
Os incrementos de controle, obtidos pela adição de sulfato de amônio à calda, mantiveram-se evidentes nas avaliações conduzidas aos 21 e 28 DAA. Nessas datas, a adição de 2,5, 5 e $10 \mathrm{~g} \mathrm{~L}^{-1}$ de sulfato de amônio continuaram a proporcionar níveis de controle iguais à dose de $720 \mathrm{~g} \mathrm{ha}^{-1}$ de e.a. do produto.

Para caldas provenientes de água dura (altos teores de cálcio e magnésio), a maior eficácia do glifosato, em presença do sulfato de amônio, tem sido explicada pela ligação do $\mathrm{Ca}^{2+}$ com o ânion sulfato, que forma precipitados de $\mathrm{CaSO}_{4}$. Com a remoção do cálcio, o íon $\mathrm{NH}_{4}^{+}$pode se ligar ao glifosato e gerar um sal que atravessa mais facilmente a cutícula (Thelen et al., 1995). Porém, no presente trabalho, os incrementos provenientes da adição de fontes nitrogenadas à calda devem estar relacionados a outras vias de resposta, que não a redução da atividade de cátions antagônicos, pois a água utilizada não continha teores elevados de cálcio, magnésio, ferro ou dureza total (Tabela 2). Nurse et al. (2008) também observaram que a adição de sulfato de amônio $\left(20 \mathrm{~g} \mathrm{~L}^{-1}\right)$ à calda com

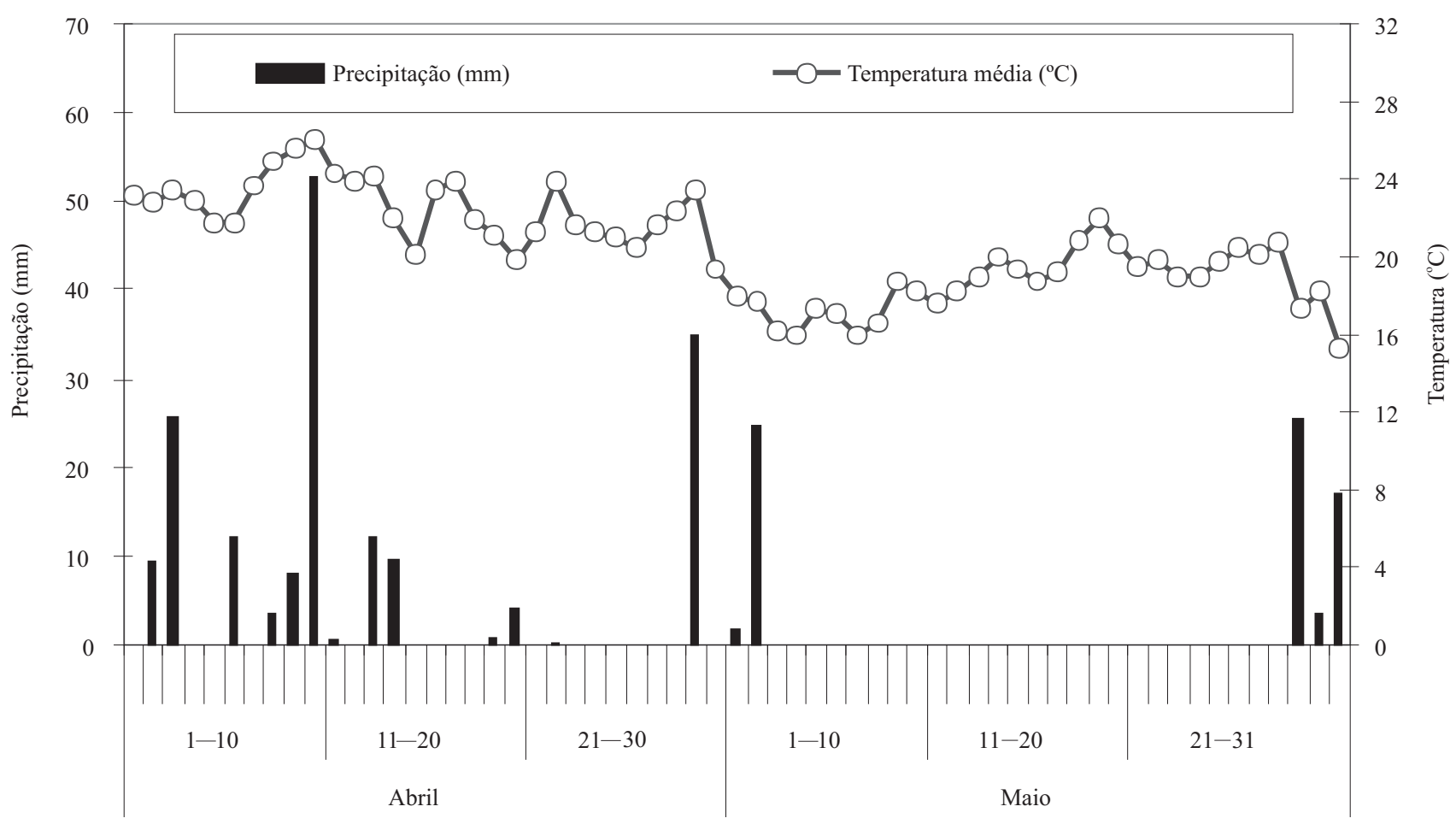

Meses/dias (2008)

Figura 1. Temperatura média e precipitações diárias, observadas durante o período de condução dos experimentos em campo. Piracicaba, SP, 2008. 
água de boa qualidade proporciona melhor controle de algumas espécies de plantas daninhas, porém somente em doses inferiores às recomendadas, o que é corroborado pelos resultados do presente trabalho.

Young et al. (2003) comentam que a acidificação da calda, provocada pelo sulfato de amônio, permitiria que mais moléculas de glifosato permanecessem sob a forma não dissociada, que atravessa a membrana plasmática com maior facilidade. Dentro das células, em razão do $\mathrm{pH}$ mais alcalino que o do meio inter-celular, as moléculas de glifosato passariam novamente para a forma dissociada e atuariam como herbicidas. Outra teoria, que também pode explicar os incrementos de controle, observados com a adição de sulfato de amônio à calda com glifosato, indica a alteração na morfologia das gotas em razão dessa adição, que atrasa ou impede a cristalização do glifosato na superfície foliar. Desta forma, tem-se mais tempo para que a molécula atravesse a cutícula (MacIsaac et al., 1991).

A adição de $20 \mathrm{~g} \mathrm{~L}^{-1}$ de sulfato de amônio $\left(4 \mathrm{~kg} \mathrm{ha}^{-1}\right)$ à calda não incrementou nem reduziu o controle (Tabela 3). Esse resultado pode indicar o início de efeito antagônico, resultante da adição excessiva do fertilizante. Salisbury et al. (1991) também estudaram a adição de sulfato de amônio à calda de pulverização, para incremento no controle de capim-massambará, com o herbicida glifosato. Constataram que a adição de sulfato de amônio (3,33 $\left.\mathrm{kg} \mathrm{ha}^{-1}\right)$ à calda de $420 \mathrm{~g} \mathrm{ha}^{-1}$ de e.a. de glifosato proporcionou controle comparável à dose de $840 \mathrm{~g} \mathrm{ha}^{-1}$ de e.a., e que efeitos antagônicos só foram observados com doses de sulfato de amônio superiores a 9,7 $\mathrm{kg} \mathrm{ha}^{-1}$. Ao comparar doses de sulfato de amônio, Donald (1988) também concluiu

Tabela 2. Resultados analíticos da água utilizada nas aplicações, previamente submetida a tratamento usual para a distribuição pública.

\begin{tabular}{|c|c|c|c|}
\hline Parâmetro & Quantidade $\left(\mathrm{mg} \mathrm{L}^{-1}\right)$ & Parâmetro & Quantidade \\
\hline Cloreto $\left(\mathrm{Cl}^{-}\right)$ & 26,0 & Zinco & $0,09 \mathrm{~g} \mathrm{~L}^{-1}$ \\
\hline Nitrato $\left(\mathrm{N}-\mathrm{NO}_{3}\right)$ & 11,5 & Alcalinidade $\left(2 \mathrm{CO}_{3}{ }^{2-}+\mathrm{HCO}_{3}^{-}\right)$ & $40,2 \mathrm{mg} \mathrm{L}^{-1}$ \\
\hline Sulfato $\left(\mathrm{SO}_{4}{ }^{2-}\right)$ & 68,3 & Nitrogênio amoniacal $\left(\mathrm{N}-\mathrm{NH}_{3}\right)$ & $0,2 \mathrm{mg} \mathrm{L}^{-1}$ \\
\hline Fósforo $(\mathrm{P})$ & 0,01 & Cor aparente & $0,0 \mathrm{PtCo}$ \\
\hline Sódio $\left(\mathrm{Na}^{+}\right)$ & 36,5 & Turbidez & 0,0 FTU \\
\hline Potássio $\left(\mathrm{K}^{+}\right)$ & 4,8 & Sedimentos em suspensão & $1,0 \mathrm{mg} \mathrm{L}^{-1}$ \\
\hline Cálcio $\left(\mathrm{Ca}^{2+}\right)$ & 38,8 & Condutividade elétrica (CE) & $0,26 \mathrm{mS} \mathrm{cm}^{-1}$ \\
\hline Magnésio $\left(\mathrm{Mg}^{2+}\right)$ & $\begin{array}{r}3,0 \\
2,7\end{array}$ & $\mathrm{pH}$ & 8,2 \\
\hline Ferro $(\mathrm{Fe})$ & 0,02 & Gás carbônico $\left(\mathrm{CO}_{2}\right)$ & $0,4 \mathrm{mg} \mathrm{L}^{-1}$ \\
\hline Cobre $(\mathrm{Cu})$ & 0,0 & Acidez $\left(\mathrm{CaCO}_{3}\right)$ & $1,0 \mathrm{mg} \mathrm{L}^{-1}$ \\
\hline Manganês (Mn) & 0,02 & Dureza total $\left(\mathrm{CaCO}_{3}\right)^{(1)}$ & $107,8 \mathrm{mg} \mathrm{L}^{-1}$ \\
\hline
\end{tabular}

${ }^{(1)}$ Dureza total calculada com base no equivalente de carbonato de cálcio $\left(\mathrm{CaCO}_{3}\right)$, segundo Franson $(1995): 2,497\left[\mathrm{Ca}, \mathrm{mg} \mathrm{L}^{-1}\right]+4,118\left[\mathrm{Mg}, \mathrm{mg} \mathrm{L}^{-1}\right]$.

Tabela 3. Controle percentual e massa de matéria seca média das plantas daninhas, dos experimentos desenvolvidos em campo, após a aplicação de 11 tratamentos herbicidas, com adição de diferentes doses de fontes nitrogenadas (FN), avaliados aos 14, 21 e 28 dias após a aplicação (DAA) $)^{(1)}$.

\begin{tabular}{|c|c|c|c|c|}
\hline \multirow[t]{2}{*}{ Tratamento } & \multicolumn{3}{|c|}{ Controle percentual } & \multirow[t]{2}{*}{ Massa de matéria seca $\left(\mathrm{g} \mathrm{m}^{-2}\right)$} \\
\hline & 14 DAA & $21 \mathrm{DAA}$ & $28 \mathrm{DAA}$ & \\
\hline Testemunha sem aplicação & $0,0 \mathrm{C}$ & $0,0 \mathrm{C}$ & $0,0 \mathrm{C}$ & $584,2 \mathrm{~B}$ \\
\hline Glifosato $360 \mathrm{~g} \mathrm{ha}^{-1}$ & $72,0 \mathrm{~B}$ & $82,7 \mathrm{~B}$ & $87,5 \mathrm{~B}$ & $239,9 \mathrm{~A}$ \\
\hline Glifosato $360 \mathrm{~g} \mathrm{ha}^{-1}+\mathrm{SA} 2,5 \mathrm{~g} \mathrm{~L}^{-1}$ & $81,7 \mathrm{~A}$ & $90,8 \mathrm{~A}$ & $93,5 \mathrm{~A}$ & $191,8 \mathrm{~A}$ \\
\hline Glifosato $360 \mathrm{~g} \mathrm{ha}^{-1}+\mathrm{SA}_{5} \mathrm{~g} \mathrm{~L}^{-1}$ & $77,5 \mathrm{~B}$ & $89,8 \mathrm{~A}$ & $93,3 \mathrm{~A}$ & $200,5 \mathrm{~A}$ \\
\hline Glifosato $360 \mathrm{~g} \mathrm{ha}^{-1}+\mathrm{SA} 10 \mathrm{~g} \mathrm{~L}^{-1}$ & $84,0 \mathrm{~A}$ & $91,2 \mathrm{~A}$ & $94,3 \mathrm{~A}$ & $223,3 \mathrm{~A}$ \\
\hline Glifosato $360 \mathrm{~g} \mathrm{ha}^{-1}+$ SA $20 \mathrm{~g} \mathrm{~L}^{-1}$ & $76,7 \mathrm{~B}$ & $84,8 \mathrm{~B}$ & $89,3 \mathrm{~B}$ & $196,1 \mathrm{~A}$ \\
\hline Glifosato $360 \mathrm{~g} \mathrm{ha}^{-1}+$ uréia $1,5 \mathrm{~g} \mathrm{~L}^{-1}$ & $75,8 \mathrm{~B}$ & $86,3 \mathrm{~B}$ & $91,2 \mathrm{~B}$ & $173,1 \mathrm{~A}$ \\
\hline Glifosato $360 \mathrm{~g} \mathrm{ha}^{-1}+$ uréia $3 \mathrm{~g} \mathrm{~L}^{-1}$ & $75,7 \mathrm{~B}$ & $85,3 \mathrm{~B}$ & $88,3 \mathrm{~B}$ & $209,1 \mathrm{~A}$ \\
\hline Glifosato $360 \mathrm{~g} \mathrm{ha}^{-1}+$ uréia $6 \mathrm{~g} \mathrm{~L}^{-1}$ & $73,7 \mathrm{~B}$ & $85,7 \mathrm{~B}$ & $88,8 \mathrm{~B}$ & $207,8 \mathrm{~A}$ \\
\hline Glifosato $360 \mathrm{~g} \mathrm{ha}^{-1}+$ uréia $12 \mathrm{~g} \mathrm{~L}^{-1}$ & $75,5 \mathrm{~B}$ & $85,2 \mathrm{~B}$ & $89,0 \mathrm{~B}$ & $208,9 \mathrm{~A}$ \\
\hline Glifosato $720 \mathrm{~g} \mathrm{ha}^{-1}$ & $90,8 \mathrm{~A}$ & $94,5 \mathrm{~A}$ & $96,3 \mathrm{~A}$ & $151,8 \mathrm{~A}$ \\
\hline $\mathrm{F}_{\text {(entre experimentos) }}$ & $3,407^{\mathrm{ns}}$ & $0,446^{\mathrm{ns}}$ & $0,239^{\mathrm{ns}}$ & $1,577^{\mathrm{ns}}$ \\
\hline $\mathrm{F}_{\text {(tratamentos) }}$ & $56,819 * *$ & $136,596 * *$ & $180,869 * *$ & $38,342 * *$ \\
\hline $\mathrm{F}_{\text {(interação tratamentos x experimentos) }}$ & $0,952^{\mathrm{ns}}$ & $0,808^{\mathrm{ns}}$ & $0,221^{\mathrm{ns}}$ & $1,006^{\mathrm{ns}}$ \\
\hline CV $(\%)$ & 11,05 & 6,94 & 6,07 & 19,87 \\
\hline
\end{tabular}

${ }^{(1)}$ Médias seguidas por letras iguais, nas colunas, não diferem entre si pelo teste de Scott-Knott, a 5\% de probabilidade; SA: sulfato de amônio. ns Não-significativo. **Significativo pelo teste $\mathrm{F}$, a $1 \%$ de probabilidade. 
que concentrações de 56 e $110 \mathrm{~g} \mathrm{~L}^{-1}$ não foram mais benéficas que a de $28 \mathrm{~g} \mathrm{~L}^{-1}$, para o controle de Hordeum jubatum.

A adição de $20 \mathrm{~g} \mathrm{~L}^{-1}$ de sulfato de amônio à calda de herbicidas é prática corriqueira para a análise de adjuvantes. Maschhoff et al. (2000) e Young et al. (2003) observaram que essa concentração de sulfato de amônio proporciona maior absorção e, conseqüentemente, maior translocação de glifosato e glufosinato, por Abutilon theophrasti. Ainda, Costa \& Appleby (1986), Pratt et al. (2003) e Mueller et al. (2006) observaram melhor controle, de diferentes espécies de plantas daninhas, quando adicionaram $20 \mathrm{~g} \mathrm{~L}^{-1}$ de sulfato de amônio à calda do herbicida. Jordan et al. (1997) observaram incremento no controle de Sida spinosa e Ipomoea hederacea var. intergriuscula, com a adição de sulfato de amônio $\left(17,5-20 \mathrm{~g} \mathrm{~L}^{-1}\right)$ à calda do herbicida glifosato.

As diferenças observadas nas avaliações de controle, com adição de sulfato de amônio, não foram observadas na análise da massa de matéria seca (Tabela 3), o que indica ser essa variável menos sensível a pequenas variações. Para maior sensibilidade na análise de massa, pode-se optar por maior número de repetições, maior número de amostragens por parcela ou instalação de experimentos em áreas semeadas com quantidades exatas de propágulos da espécie de interesse.

Nos experimentos em campo, não foram observados incrementos de controle resultantes da adição de uréia à calda do herbicida glifosato (Tabela 3 ). Ao estudar o efeito da adição de adjuvantes à calda do glifosato, para controle de capim-colonião (Panicum maximum), Durigan (1992) constatou que a adição de uréia (2 $\left.\mathrm{g} \mathrm{L}^{-1}\right)$ proporcionou redução da dose de glifosato em 360 g ha $^{-1}$ de e.a. Suwunnamek \& Parker (1975) observaram que a adição de uréia, fosfato-butil-amônio e fosfato de amônio também elevaram o controle de tiririca (Cyperus rotundus) pelo glifosato, porém não apresentaram vantagens em relação à adição de sulfato de amônio.

No que se refere ao controle da trapoeraba, nenhum tratamento com o herbicida glifosato foi eficaz no manejo em condição de casa de vegetação, em quaisquer das avaliações realizadas (Tabela 4). Aos 14 DAA, o maior nível de controle foi obtido com a aplicação de glifosato a $1.440 \mathrm{~g} \mathrm{ha}^{-1}$ de e.a., porém limitou-se a apenas $50 \%$ de controle. Adicionalmente, todos os tratamentos com a menor dose do herbicida diferenciaram-se da maior dose, sem evidência do efeito da adição das fontes nitrogenadas à calda (Tabela 4). Esses resultados estão em concordância com o trabalho de Culpepper et al. (2004), que também não observaram controle adequado da trapoeraba, com aplicações isoladas de glifosato, e que necessitou de complementação com herbicidas com outro mecanismo de ação. Timossi et al. (2006) observaram que a aplicação de $1.440 \mathrm{~g} \mathrm{ha}^{-1}$ de e.a. de glifosato foi eficaz para o manejo da comunidade infestante, porém as plantas de trapoeraba mostraram-se tolerantes ao glifosato em doses de até $2.880 \mathrm{~g} \mathrm{ha}^{-1}$ e.a.

Ao estudar a absorção, translocação e metabolismo do glifosato, em plantas daninhas, Monquero et al. (2004)

Tabela 4. Controle percentual e massa de matéria seca da trapoeraba (Commelina benghalensis), após aplicação de 11 tratamentos herbicidas, com adição de diferentes doses de fontes nitrogenadas (FN), avaliados aos 14, 21 e 28 dias após aplicação (DAA) ${ }^{(1)}$.

\begin{tabular}{|c|c|c|c|c|}
\hline \multirow[t]{2}{*}{ Tratamento } & \multicolumn{3}{|c|}{ Controle percentual } & \multirow{2}{*}{$\begin{array}{c}\text { Massa de matéria seca } \\
\text { (g por parcela) }\end{array}$} \\
\hline & $14 \mathrm{DAA}$ & $21 \mathrm{DAA}$ & 28 DAA & \\
\hline Testemunha sem aplicação & $0,0 \mathrm{C}$ & $0,0 \mathrm{~B}$ & $0,0 \mathrm{C}$ & $7,3 \mathrm{~B}$ \\
\hline Glifosato $720 \mathrm{~g} \mathrm{ha}^{-1}$ & $30,0 \mathrm{~B}$ & $47,6 \mathrm{~A}$ & $44,0 \mathrm{~B}$ & $4,6 \mathrm{~A}$ \\
\hline Glifosato $720 \mathrm{~g} \mathrm{ha}^{-1}+$ SA $2,5 \mathrm{~g} \mathrm{~L}^{-1}$ & $29,0 \mathrm{~B}$ & $44,8 \mathrm{~A}$ & $46,0 \mathrm{~B}$ & $4,1 \mathrm{~A}$ \\
\hline Glifosato $720 \mathrm{~g} \mathrm{ha}^{-1}+$ SA $5 \mathrm{~g} \mathrm{~L}^{-1}$ & $28,6 \mathrm{~B}$ & $46,0 \mathrm{~A}$ & $43,0 \mathrm{~B}$ & $4,1 \mathrm{~A}$ \\
\hline Glifosato $720 \mathrm{~g} \mathrm{ha}^{-1}+\mathrm{SA} 10 \mathrm{~g} \mathrm{~L}^{-1}$ & $32,2 \mathrm{~B}$ & $48,0 \mathrm{~A}$ & $51,0 \mathrm{~B}$ & $3,6 \mathrm{~A}$ \\
\hline Glifosato $720 \mathrm{~g} \mathrm{ha}^{-1}+\mathrm{SA} 20 \mathrm{~g} \mathrm{~L}^{-1}$ & $29,0 \mathrm{~B}$ & $48,2 \mathrm{~A}$ & $47,4 \mathrm{~B}$ & $4,0 \mathrm{~A}$ \\
\hline Glifosato $720 \mathrm{~g} \mathrm{ha}^{-1}+$ uréia $1,5 \mathrm{~g} \mathrm{~L}^{-1}$ & $29,6 \mathrm{~B}$ & $48,4 \mathrm{~A}$ & $54,0 \mathrm{~A}$ & $3,6 \mathrm{~A}$ \\
\hline Glifosato $720 \mathrm{~g} \mathrm{ha}^{-1}+$ uréia $3 \mathrm{~g} \mathrm{~L}^{-1}$ & $30,2 \mathrm{~B}$ & $46,4 \mathrm{~A}$ & $44,0 \mathrm{~B}$ & $3,6 \mathrm{~A}$ \\
\hline Glifosato $720 \mathrm{~g} \mathrm{ha}^{-1}+$ uréia $6 \mathrm{~g} \mathrm{~L}^{-1}$ & $37,6 \mathrm{~B}$ & $52,6 \mathrm{~A}$ & $58,0 \mathrm{~A}$ & $3,1 \mathrm{~A}$ \\
\hline Glifosato $720 \mathrm{~g} \mathrm{ha}^{-1}+$ uréia $12 \mathrm{~g} \mathrm{~L}^{-1}$ & $32,0 \mathrm{~B}$ & $48,8 \mathrm{~A}$ & $47,0 \mathrm{~B}$ & $3,8 \mathrm{~A}$ \\
\hline Glifosato $1.440 \mathrm{~g} \mathrm{ha}^{-1}$ & $50,4 \mathrm{~A}$ & $59,0 \mathrm{~A}$ & $61,4 \mathrm{~A}$ & $2,8 \mathrm{~A}$ \\
\hline $\mathrm{F}_{\text {(tratamentos) }}$ & $6,794 * *$ & $14,910 * *$ & $12,736^{* *}$ & $9,493 * *$ \\
\hline $\mathrm{CV}(\%)$ & 33,82 & 19,86 & 22,40 & 21,97 \\
\hline
\end{tabular}

${ }^{(1)}$ Médias seguidas por letras iguais, nas colunas, não diferem entre si pelo teste de Scott-Knott, a 5\% de probabilidade; SA: sulfato de amônio. **Significativo pelo teste $\mathrm{F}$, a $1 \%$ de probabilidade. 
encontraram o metabólito ácido aminometilfosfônico (AMPA), em plantas de trapoeraba, o que evidencia que a espécie é capaz de converter a molécula de glifosato a compostos menos tóxicos. Concluíram que a absorção diferencial e o metabolismo do glifosato são os mecanismos envolvidos na maior tolerância da espécie ao herbicida. Nesse sentido, Pline et al. (1999) observaram que a adição de sulfato de amônio à calda de herbicidas não altera as taxas de metabolismo do glufosinato de amônio nas plantas. Portanto, isto indica que a adição de sulfato de amônio à calda do glifosato pode ser uma técnica eficiente de incremento de controle, porém aplicável a plantas que não tenham rotas de detoxificação deste herbicida.

Aos 21 DAA, novamente, o maior controle obtido com a aplicação de glifosato sobre a trapoeraba não foi considerado satisfatório e, nesse caso, não foram observadas diferenças em quaisquer dos tratamentos herbicidas. Vale ressaltar que, no momento da aplicação, as plantas de trapoeraba estavam em estádio avançado de desenvolvimento vegetativo, o que pode ter contribuído para os menores controles averiguados, sem atividade das fontes nitrogenadas. Em contrapartida, aos 28 DAA, a adição de 1,5 e $6 \mathrm{~g} \mathrm{~L}^{-1}$ de uréia à calda, na menor dose do glifosato, resultou em igualdade à aplicação isolada da maior dose do produto (Tabela 4).

Com relação à uréia, Durigan (1992) comenta tratar-se de uma substância que atravessa com relativa facilidade a cutícula das folhas. Mesmo sem receber energia metabólica, passa do apoplasto para o simplasto foliar, por difusão facilitada, resultante do acúmulo de energia cinética pelas moléculas. A uréia também pode romper algumas ligações éster, éter e di-éter da cutina, o que contribui para a maior absorção de outros elementos presentes na calda, por conseqüência do aumento dos espaços de entrada. Provavelmente, esta foi a causa dos pequenos incrementos de controle observados nas avaliações de controle do glifosato em trapoeraba, aos 28 DAA (Tabela 4).

A variável massa de matéria seca da trapoeraba não apresentou diferenças entre os tratamentos herbicidas, com valores superiores apenas na testemunha, sem aplicação (Tabela 4). Esta constatação está em concordância com as avaliações em campo, em que o efeito da adição de fontes nitrogenadas à calda do herbicida glifosato não resultou em diferenças de massa. É provável que isso seja conseqüência da maior variabilidade, intrínseca a esses dados.

\section{Conclusões}

1. A adição de sulfato de amônio à calda do herbicida glifosato (360 $\mathrm{g} \mathrm{ha}^{-1}$ de e.a.) promove incrementos no controle de plantas daninhas em campo, com o uso de concentrações de até $10 \mathrm{~g} \mathrm{~L}^{-1}$.

2. O herbicida glifosato não é eficaz para o controle da trapoeraba, e não há efeito da adição de sulfato de amônio sobre esse controle.

3. A adição de uréia à calda de glifosato, na dose $360 \mathrm{~g} \mathrm{ha}^{-1}$ de e.a., melhora o controle da trapoeraba, com concentrações até $6 \mathrm{~g} \mathrm{~L}^{-1}$.

\section{Agradecimentos}

Ao Conselho Nacional de Desenvolvimento Científico e Tecnológico, por concessão de bolsas.

\section{Referências}

CHRISTOFFOLETI, P.J.; CARVALHO, S.J.P. de; LÓPEZOVEJERO, R.F.; NICOLAI, M.; HIDALGO, E.; SILVA, J.E. da. Conservation of natural resources in Brazilian agriculture: implications on weed biology and management. Crop Protection, v.26, p.383-389, 2007.

CHRISTOFFOLETI, P.J.; GALLI, A.J.B.; CARVALHO, S.J.P.; MOREIRA, M.S.; NICOLAI, M.; FOLONI, L.L; MARTINS, B.A.B.; RIBEIRO, D.N. Glyphosate sustainability in South American cropping systems. Pest Management Science, v.64, p.422-427, 2008.

COSTA, J.; APPLEBY, A.P. Effects of ammonium sulphate on leaf growth inhibition by glyphosate in Cyperus esculentus L. Crop Protection, v.5, p.314-318, 1986.

CULPEPPER, A.S.; FLANDERS, J.T.; YORK, A.C.; WEBSTER, T.M. Tropical spiderwort (Commelina benghalensis) control in glyphosate-resistant cotton. Weed Technology, v.18, p.432-436, 2004.

DONALD, W.W. Established foxtail barley, Hordeum jubatum, control with glyphosate plus ammonium sulfate. Weed Technology, v.2, p.364-368, 1988.

DURIGAN, J.C. Efeito de adjuvantes na calda e do estádio de desenvolvimento das plantas, no controle do capim-colonião (Panicum maximum) com glifosato. Planta Daninha, v.10, p.39-44, 1992.

FRANSON, M.A.H. Standard methods for the examination of water and wastewater. 19.ed. Washington: American Public Health Association, 1995. 1074p.

GAUVRIT, C. Glyphosate response to calcium, ethoxylated amine surfactant, and ammonium sulfate. Weed Technology, v.17, p.799-804, 2003.

JORDAN, D.L.; YORK, A.C.; GRIFFIN, J.L.; CLAY, P.A.; VIDRINE, P.R.; REYNOLDS, D.B. Influence of application 
variables on efficacy of glyphosate. Weed Technology, v.11, p.354-362, 1997.

MacISAAC, S.A.; PAUL, R.N.; DEVINE, M.D. A scanning electron microscope study of glyphosate deposits in relation to foliar uptake. Pesticide Science, v.31, p.53-64, 1991.

MASCHHOFF, J.R.; HART, S.E.; BALDWIN, J.L. Effect of ammonium sulfate on the efficacy, absorption, and translocation of glufosinate. Weed Science, v.48, p.2-6, 2000.

MONQUERO, P.A.; CHRISTOFFOLETI, P.J. Dinâmica do banco de sementes em áreas com aplicação freqüente do herbicida glyphosate. Planta Daninha, v.21, p.63-69, 2003.

MONQUERO, P.A.; CHRISTOFFOLETI, P.J.; OSUNA, M.D.; DE PRADO, R.A. Absorção, translocação e metabolismo do glyphosate por plantas tolerantes e suscetíveis a este herbicida. Planta Daninha, v.22, p.445-451, 2004.

MUELLER, T.C.; MAIN, C.L.; THOMPSON, M.A.; STECKEL, L.E. Comparison of glyphosate salts (isopropylamine, diammonium and potassium) and calcium and magnesium concentrations on the control of various weeds. Weed Technology, v.20, p.164-171, 2006.

NALEWAJA, J.D.; MATYSIAK, R. Optimizing adjuvants to overcome glyphosate antagonistic salts. Weed Technology, v.7, p.337-342, 1993.

NURSE, R.E.; HAMILL, A.S.; KELLS, J.J.; SIKKEMA, P.H. Annual weed control may be improved when AMS is added to below-label glyphosate doses in glyphosate-tolerant maize (Zea mays L.). Crop Protection, v.27, p.452-458, 2008.

O'SULLIVAN, P.A.; O'DONOVAN, J.T.; HAMMAN, W.M. Influence of non-ionic surfactants, ammonium sulphate, water quality and spray volume on the phytotoxicity of glyphosate. Canadian Journal of Plant Science, v.61, p.391-400, 1981.

PLINE, W.A.; WU, J.; HATZIOS, K.K. Absorption, translocation, and metabolism of glufosinate in five weed species as influenced by ammonium sulfate and pelargonic acid. Weed Science, v.47, p.636-643, 1999.
PRATT, D.; KELLS, J.J.; PENNER, D. Substitutes for ammonium sulfate as additives with glyphosate and glufosinate. Weed Technology, v.17, p.576-581, 2003.

RAMOS, H.H.; DURIGAN, J.C. Efeitos da qualidade da água de pulverização sobre a eficácia de herbicidas aplicados em pós-emergência. Bragantia, v.57, p.313-324, 1998.

RAMSDALE, B.K.; MESSERSMITH, C.G.; NALEWAJA, J.D. Spray volume, formulation, ammonium sulfate, and nozzle effects on glyphosate efficacy. Weed Technology, v.17, p.589-598, 2003.

RODRIGUES, B.N.; ALMEIDA, F.S. Guia de herbicidas. 5.ed. Londrina, 2005. 592p.

SALISBURY, C.D.; CHANDLER, J.M.; MERKLE, M.G. Ammonium sulfate enhancement of glyphosate and SC-0224 control of johnsongrass (Sorghum halepense). Weed Technology, v.5, p.18-21, 1991.

SCOTT, A.J.; KNOTT, M.A. Cluster analysis method for grouping means in the analysis of variance. Biometrics, v.30, p.507-512, 1974.

SUWUNNAMEK, U.; PARKER, C. Control of Cyperus rotundus with glyphosate: the influence of ammonium sulfate and other additives. Weed Research, v.15, p.13-20, 1975.

THELEN, K.D.; JACKSON, E.P.; PENNER, D. The basis for the hard-water antagonism of glyphosate activity. Weed Science, v.43, p.541-548, 1995.

TIMOSSI, P.C.; DURIGAN, J.C.; LEITE, G.J. Eficácia de glyphosate em plantas de cobertura. Planta Daninha, v.24, p.475-480, 2006.

TRIGO, E.J.; CAP, E.J. The impact of the introduction of transgenic crops in Argentinean agriculture. AgBioForum, v.6, p.87-94, 2003.

YOUNG, B.G.; KNEPP, A.W.; WAX, L.M.; HART, S.E. Glyphosate translocation in common lambsquarters (Chenopodium album) and velvetleaf (Abutilon theophrasti) in response to ammonium sulfate. Weed Science, v.51, p.151-156, 2003.

Recebido em $1^{\circ}$ de agosto de 2008 e aprovado em 13 de outubro de 2008 